Fernández, Ana; Rodríguez, Laura. Seguridad de abastecimiento energético en la Unión Europea en el contexto del conflicto gasista ruso-ucraniano.

\title{
SEGURIDAD DE ABASTECIMIENTO ENERGÉTICO EN LA UNIÓN EUROPEA EN EL CONTEXTO DEL CONFLICTO GASISTA RUSO- UCRANIANO
}

\section{ENERGY SUPPLY SECURITY IN THE EUROPEAN UNION IN THE CONTEXT OF THE GAS CONFLICT-UKRAINIAN RUSSIAN}

\author{
ANA FERNÁNDEZ \\ Universidad de Valladolid \\ afernc@unileon.es \\ LAURA RODRÍGUEZ \\ Universidad Nacional de Educación a Distancia \\ Irodriguezf@cee.uned.es \\ Fecha de recepción: mayo 2016 \\ Fecha de aceptación: noviembre 2016
}

\section{RESUMEN}

Este artículo intenta ofrecer una perspectiva general del avance del nivel de seguridad de abastecimiento energético para el gas en los Estados miembros de la Unión Europea (UE) que más compras realizan de este recurso a Rusia. Para ello se ha construido un indicador sintético: el Índice Ponderado de Seguridad Energética, que permite examinar si el grado de dicha seguridad se ha reducido en los últimos años como consecuencia del conflicto gasista ruso-ucraniano acontecido en 2006 y 2009. Los resultados ponen de manifiesto que en la mayoría de los países ha sucedido lo contrario.

PALABRAS CLAVE: seguridad de abastecimiento energético, gas, Unión Europea, Rusia, Ucrania.

\begin{abstract}
This paper attempts to provide an overview of progress in the level of security of energy supply for gas in the Member States of the European Union (EU) to more purchases made this appeal to Russia. To do this we have constructed a synthetic indicator: the Weighted Index of Energy Security, which lets examine whether the degree of such security has declined in recent years as a result of the RussianUkrainian gas conflict occurred in 2006 and 2009. The results show that in most countries the opposite has happened.
\end{abstract}

KEY WORDS: security of energy supply, gas, European Union, Russia, Ukraine.

JEL: F59, N74, Q48. 
Fernández, Ana; Rodríguez, Laura. Seguridad de abastecimiento energético en la Unión Europea en el contexto del conflicto gasista ruso-ucraniano.

\section{EL CONFLICTO DEL GAS RUSO-UCRANIANO}

\subsection{Antecedentes}

En los últimos años han sucedido enfrentamientos transcendentales entre Rusia y Ucrania, denominados "las crisis del gas", situando nuevamente en primera línea la carencia de la integración energética europea.

Desde el derrumbe de la Unión Soviética las condiciones del contrato de aprovisionamiento de gas ruso a Ucrania eran preferentes, pero la caída del muro de Berlín en 1989 y la revolución naranja ${ }^{1}$ ucraniana de 2004 desembocaron en la abolición de las causas políticas que llevaron al trato histórico. La empresa Gazprom $^{2}$ pretendió subir los precios del gas a Ucrania y ante la negativa de ésta, la compañía suspendió la provisión de este bien en el año 2006. Como respuesta, Ucrania se adueñó de parte del gas que pasa por sus tierras en tránsito hacia Europa, lo que desencadenó una pérdida del aprovisionamiento en algunos Estados miembros de la UE. El conflicto fue de carácter comercial y también político (Moré, 2006: 2).

Rusia ya había cortado el suministro de gas a Bielorrusia consiguiendo un aumento de precios y/o ventajas estratégicas. La desemejanza con Ucrania es que por ésta transcurría en 2009 el $80 \%$ del gas ruso que entra en suelo europeo Umbach (2014: 1). Una disputa ruso-ucraniana tiene consecuencias directas e inminentes para la UE.

A principios de 2009 los flujos de gas ruso con destino Ucrania y la UE se vieron nuevamente detenidos cuando Kiev se opuso a devolver el total de la deuda que mantenía con Gazprom ${ }^{3}$. Esta situación afectó a la mayoría de países ${ }^{4}$. Debido a la magnitud global del problema y pese a que la interrupción del suministro fue una decisión comercial entre la compañía Gazprom y Naftogaz ${ }^{5}$, la UE se vio obligada a ejercer un papel importante como observador internacional facilitando las negociaciones para constituir un acuerdo con el fin de restablecer el abastecimiento de gas. Estos esfuerzos culminaron con la aprobación de una alianza entre Rusia, Ucrania y la Unión (European Commission, 2009a: 4) y entre los ministros Putin y

\footnotetext{
${ }^{1}$ La revolución naranja tuvo lugar en Ucrania entre 2004 y 2005 y consistió en diversos levantamientos contra el sistema ineficaz y corrupto del presidente ucraniano en esos momentos (Leonid Kuchma), y la manipulación de los resultados de las elecciones presidenciales que se celebraron durante esos meses.

${ }^{2}$ Gazprom es una compañía rusa de energía, centrada en la exploración geológica, producción, transporte, almacenamiento, procesamiento y comercialización de gas y otros hidrocarburos. La Federación rusa controla una participación del 50,23\% en el capital social de Gazprom. Exporta gas natural al continente europeo pasando por gasoductos de Estados estratégicamente situados como Ucrania y es el líder entre las empresas petroleras y gasistas, ya que cuenta con una de las reservas de gas natural más grandes del mundo.

${ }^{3}$ Rusia siempre ha declarado que las suspensiones de gas a Ucrania se llevaron a cabo por la falta de cumplimiento de las cláusulas del contrato entre ambas regiones. No obstante, la mayoría de analistas políticos perciben estos hechos como un arma política que utiliza Rusia para ampliar su influencia y poder negociador en el entorno internacional (Marín et al., 2012: 72).

${ }^{4}$ Concretamente diecisiete Estados miembros se vieron perjudicados, de manera más acusada Polonia, Finlandia, Austria y Bulgaria.

${ }^{5}$ Naftogaz es una sociedad estatal ucraniana líder en el combustible y la energía en este país. Se trata de una compañía de petróleo y gas que busca consolidar su posición como el principal operador de tránsito de gas ruso a países europeos.
} 
Fernández, Ana; Rodríguez, Laura. Seguridad de abastecimiento energético en la Unión Europea en el contexto del conflicto gasista ruso-ucraniano.

Timoshenko quienes firmaron un convenio para poner fin a las discrepancias. Además, Gazprom y Naftogaz certificaron un contrato de abastecimiento y de tránsito por un período de una década (Pirani et al., 2009: 26). Las soluciones de emergencia aplicadas por la Unión durante la crisis incluyeron una mayor diversificación energética y de rutas.

Un año después de las disputas el Parlamento Europeo declaró que una interrupción considerable del abastecimiento de gas a la UE puede perjudicar a todos los Estados, a la Unión en su conjunto y a los integrantes del Tratado de la Comunidad de la Energía 6 . Puede suscitar daños profundos en su economía y ocasionar efectos sociales transcendentales, especialmente en los clientes más débiles.

\subsection{Situación contemporánea}

En marzo de 2014 germinó el tercer conflicto del gas entre Rusia y Ucrania originado por la adhesión de Crimea (región clave geoestratégica) a territorio ruso. Gazprom dejó de asignar los descuentos que se aplicaban en la facturación a Ucrania por la acumulación de deudas. Un acuerdo avalaría el aprovisionamiento de gas a la UE y a Ucrania durante la época invernal, pero la realidad es que la estabilidad del suministro de gas ruso a ambos territorios obedece a varias circunstancias de las cuales solamente algunas pueden ser controladas por la Unión. Todo ello ha puesto en evidencia el vínculo entre la política internacional y la seguridad de abastecimiento energético.

Desde la primavera de 2014 la UE está realizando empeños notables a través de reuniones con autoridades rusas y ucranianas con el fin de pactar acuerdos entre ambas regiones a raíz de sus problemas por las deudas y los pagos del gas, intentando de esta manera asegurar entregas suficientes a Ucrania y al conjunto de la Unión (European Commission, 2014b: 3).

Según el nuevo informe de la Comisión Europea denominado "La capacidad de resistencia del sistema de gas europeo. Preparación para una posible interrupción del suministro procedente del Este durante el otoño e invierno de 2014/2015" en un marco de cooperación entre los países miembros menos ciudadanos se verían desprovistos de gas. Si los Estados miembros no colaboran entre ellos, en un escenario de corte durante seis meses en Bulgaria, Rumania, Serbia, la Antigua República Yugoslava de Macedonia y Bosnia se extraviaría el $40 \%$ del suministro. Una cifra similar se perdería en Lituania, Estonia y Finlandia. Además, Hungría se vería perjudicada (con un déficit del 30\%) y Polonia con un 20\% (European Commission, 2014b: 6).

Si se paralizan las entradas de gas a través de Ucrania las naciones del sudeste de Europa (Bulgaria y Rumania) serían las más perjudicadas. Las zonas del este (Hungría, Eslovaquia y la República Checa) también se verían afectadas. En el caso de una interrupción de larga duración Italia (tercer mercado de gas más amplio de la

\footnotetext{
${ }^{6}$ Los miembros de la Comunidad de la Energía son la Comunidad Europea, Albania, Bosnia y Herzegovina, Croacia, la Antigua República Yugoslava de Macedonia, Montenegro, Serbia y la Misión de Administración Provisional de las Naciones Unidas en Kosovo de conformidad con la Resolución 1244 del Consejo de Seguridad de las Naciones Unidas.
} 
Fernández, Ana; Rodríguez, Laura. Seguridad de abastecimiento energético en la Unión Europea en el contexto del conflicto gasista ruso-ucraniano.

Unión) se vería damnificada. Aun así, las secuelas serían más modestas que en 2009, gracias a que el gasoducto Nord Stream ${ }^{7}$ ya está finalizado, otras interconexiones han mejorado el trance en el este de Europa y la situación económica ha mejorado (Pirani et al., 2014: 20). Umbach (2014: 1) añade que ahora se puede comprar más gas natural licuado, en 2014 el gas ruso que circula por gasoductos ucranianos hacia la UE se redujo al 53\% (comparado con el $80 \%$ de 2009) gracias a las modernas tuberías y las nuevas interconexiones gasistas entre Europa Oriental y Central han intercomunicado algunas de las "islas energéticas" de la Unión Europea. Si Rumania, Bulgaria, Grecia, Chipre y Croacia fomentaran sus particulares planes de gas convencional submarino y terrestre podrían ampliar su producción, así como vender este recurso mediante canales más cortos y baratos que los rusos a otras regiones del continente.

\section{SEGURIDAD DE ABASTECIMIENTO ENERGÉTICO}

\subsection{Concepto}

La seguridad de abastecimiento energético8 también se conoce con el nombre de seguridad energética, seguridad de suministro o de aprovisionamiento. En los países importadores se utilizan estos conceptos como si fueran sinónimos. Sin embargo, hay que considerar que no sólo afecta a los consumidores o demandantes de energía, sino que además influye de forma directa en los países productores que en muchas ocasiones, dependen en gran medida de las ganancias por ventas de energía para satisfacer las necesidades básicas de las economías (Marín et al., 2012: 68).

Siguiendo a Chester (2010: 887) la seguridad energética puede albergar múltiples dimensiones y admite distintas especificidades en función del país, período temporal o fuente energética a la que se aplique. Por esta razón, aunque la seguridad de suministro es de gran relevancia para las políticas energéticas de los países diversos autores han afirmado que no se encuentra claramente definida. Tal es el caso de Kruyt et al. (2009: 2166) que declara que "todavía no hay consenso sobre su interpretación precisa" y de Alhajji (2007: 1), que hace una crítica a la literatura de la energía porque según él no se ha logrado llegar a una definición con la que la mayoría de las personas pueda estar de acuerdo. En palabras de Zapater (2009: 54) el término es en sí mismo "impreciso y complejo" ya que engloba cuestiones de diversa naturaleza y en las de Yunta (2008: 139) es "sencillo aunque impreciso". En una línea semejante aparecen otras aportaciones que señalan que es un concepto "borroso" (Löschel et al., 2010: 1607). La combinación de estas exposiciones hace que el término sea difícil de medir y equilibrar contra otros objetivos estatales (Winzer, 2012: 36).

\footnotetext{
${ }^{7}$ Transporta gas ruso a Alemania sin atravesar Ucrania o Bielorrusia a través del mar Báltico, ampliando así la capacidad de transporte en la UE y permitiendo rutas de transporte alternativas, a la vez que reduce costes de traslado del gas de Rusia y suprime los posibles riesgos políticos.

8 La seguridad de abastecimiento energético, la seguridad de suministro energético, la seguridad de aprovisionamiento energético o de modo más abreviado la seguridad energética o la seguridad del suministro se emplean como sinónimos tanto en este artículo como en otras partes de la literatura.
} 
Fernández, Ana; Rodríguez, Laura. Seguridad de abastecimiento energético en la Unión Europea en el contexto del conflicto gasista ruso-ucraniano.

El planteamiento tradicional que se dio a la seguridad del suministro fue de naturaleza geopolítica. El interés se centró en avalar el aprovisionamiento de combustible necesario para las actividades de las industrias (Mena, 2013: 68). No obstante, este planteamiento tiene en cuenta solamente una pieza del dilema ya que hay que considerar que el concepto objeto de investigación alude a los Estados consumidores o demandantes de energía (en este caso llamada "seguridad del abastecimiento energético") y a los Estados productores (también denominada "seguridad de demanda o de exportación energética"). Ambos puntos de vista se encuentran enlazados (Marín et al., 2012: 68). En este trabajo se tendrá en cuenta la seguridad energética desde el punto de vista de los consumidores.

Posteriormente se han ido añadiendo otros factores que afectan a la estabilidad de suministro (conflictos políticos, retos medioambientales, etc.) y a los precios de la energía (APERC, 2007: 5). En conclusión, la noción de seguridad energética ha ido cambiando con el paso del tiempo.

A la hora de analizar la noción de la seguridad energética es interesante distinguir entre las asociaciones y autores que interpretan la definición desde una perspectiva amplia y los que lo hacen desde una perspectiva más estrecha. Entre los primeros sobresale la visión de la UE, que en el año 2000 abordó el tema en su Libro Verde "Hacia una estrategia europea de la seguridad del abastecimiento energético", incluyendo el elemento de la sostenibilidad del medio ambiente. De acuerdo con éste, el principal objetivo de una estrategia energética debe ser

"garantizar, para el bienestar de sus ciudadanos y para el buen funcionamiento de la economía, la disponibilidad física ininterrumpida de los productos energéticos en el mercado a un precio asequible para todos los consumidores, respetando al mismo tiempo las preocupaciones ambientales y mirando hacia el desarrollo sostenible. La seguridad del abastecimiento no pretende maximizar la autonomía energética o minimizar la dependencia, sino que tiene como objetivo reducir los riesgos relacionados con tal dependencia: el equilibrio y la diversificación de las distintas fuentes de suministro" (European Commission, 2000: 2).

En contraste, para los segundos la definición más generalizada de seguridad de abastecimiento energético es la de "disponibilidad de una oferta adecuada de energía a precios asumibles" (Escribano, 2006: 3). En otras palabras, la seguridad energética alude a la pérdida de bienestar económico que puede suceder como consecuencia de una variación del precio o de la disponibilidad de la energía (Bohi y Toman, 1996: 1). Segoviano (2011: 7) critica esta descripción por ser insostenible, ya que abarca solamente los consumidores de energía dejando de lado otras variables que participan en los movimientos energéticos como por ejemplo la demanda de las comarcas productoras, los riesgos procedentes de las paradas de provisiones y el papel que desempeñan actores no gubernativos en el ejercicio geopolítico.

De acuerdo con la literatura disponible existen diferentes perspectivas del significado del concepto, es decir, aparece repartida entre los autores que entienden la seguridad de abastecimiento desde un punto de vista económico y los que lo hacen desde una perspectiva política y estratégica (Checchi, et al., 2009: 1). Según estos autores, los primeros consideran la seguridad energética sin sentido, ya que piensan que las cuestiones de la energía se rigen por el mercado, solicitando la intervención de los gobiernos únicamente cuando los mercados fracasan. Por el contrario, los segundos creen que las naciones han hecho de la expresión una discusión de 
Fernández, Ana; Rodríguez, Laura. Seguridad de abastecimiento energético en la Unión Europea en el contexto del conflicto gasista ruso-ucraniano.

seguridad estatal. La declaración de Bohi y Toman en 1996 simboliza un ejemplo del grupo con perspectivas económicas y la del Libro Verde de la Comisión Europea en el año 2000 de la siguiente agrupación. Finalmente los dos aspectos son aceptados e indispensables, el económico y el político: son dos caras de la misma moneda que se perfeccionan entre sí (Rodríguez y García-Verdugo, 2012: 232).

A pesar de que no hay una interpretación universal, existen algunas peculiaridades que se incorporan a la definición en la mayoría de las ocasiones: la disponibilidad física y los precios (Checchi, et al., 2009: 1).

El concepto que se adopta en este artículo es el reflejado en el Libro Verde del año 2000, por ser la Unión Europea el objeto de observación del presente trabajo.

\subsection{Dimensiones}

Para describir las dimensiones de la seguridad del suministro que nos ayudarán a cuantificarla en la fase objeto de estudio (2005-2010)9 se pueden usar los riesgos energéticos, ya que la misma depende de forma directa de la existencia de ellos y de su impacto efectivo (Rodríguez y García-Verdugo, 2012: 231). Cabe decir que la complejidad del concepto de seguridad energética se traslada a los riesgos que provocan dicha seguridad. Según Muñoz (2012: 278) los riesgos para la seguridad de aprovisionamiento son un fenómeno multidimensional y una de las desventajas es que las clasificaciones atienden a criterios dispares y además es inusual que se señale la regla manejada.

La seguridad de abastecimiento posee dimensiones físicas, económicas, sociales y ambientales (European Commission 2000: 2). En línea con el debate sobre la seguridad energética en Europa Checchi et al. (2009: 3) proponen cinco clases de dimensiones: geopolíticas, geológicas, económicas, técnicas y ambientales.

Al mismo tiempo la seguridad de aprovisionamiento puede ser examinada desde una perspectiva a corto plazo o a largo plazo (Costantini et al., 2007; Yunta, 2008; IEA, 2014). La primera está vinculada a la vulnerabilidad de una determinada estructura, es decir, la intranquilidad se concentra en las secuelas de los cortes inesperados del aprovisionamiento o en el incremento de precios de las materias primas energéticas. Por el contrario, a largo plazo la inquietud se centra en la disponibilidad de energía apta para un desarrollo económico sostenible y estable (Yunta, 2008: 140). Finalmente ambas contingencias están conectadas.

Los estudios precedentes plantean una organización no causal de los riesgos energéticos fundamentada bien en el horizonte temporal o bien en la descripción del término. En cambio, este artículo se basará en los estudios que clasifican los orígenes de los riesgos energéticos para explicar la seguridad energética

\footnotetext{
${ }^{9}$ Se ha elegido este intervalo porque se considera que es el que más se ajusta al contexto de las principales crisis del gas entre Rusia y Ucrania y que a su vez tienen un impacto significativo en la UE. Este período es el considerado en las tablas 4 y 5 . Las tablas 1 y 2 se han actualizado hasta el momento en que lo ha permitido la fuente con el propósito de conseguir una óptica más reciente. Por último, en la tabla 3 se ha manejado una media del decenio comprendido entre 2002 y 2012 con el fin de conocer los países de la UE-28 más dependientes del gas ruso en los años más próximos a los conflictos del gas indicados en párrafos más arriba.
}

Papeles de Europa

Vol. 29 Núm. 2 (2016): 30-53

http://dx.doi.org/10.5209/PADE.55797 
Fernández, Ana; Rodríguez, Laura. Seguridad de abastecimiento energético en la Unión Europea en el contexto del conflicto gasista ruso-ucraniano.

centrándose en el riesgo de interrupción del suministro energético. En concreto se empleará como punto de partida la nueva propuesta realizada por los autores Rodríguez y García-Verdugo (2012: 233) con raíces en la ordenación causal de los riesgos energéticos de García-Verdugo y San Martín (2011: 124), quienes aportaron una taxonomía en función del carácter de los riesgos separando los riesgos primarios (causas) y los secundarios (efectos). Los primarios se identifican con cinco dimensiones que pueden ocasionar el riesgo de corte de suministro: la económica, la energética, la política, la social y la técnica. Los secundarios pueden conducir a tres consecuencias: interrupciones de suministro energético, daños medioambientales y daños en la salud humana y en la propiedad.

El planteamiento efectuado por Rodríguez y García-Verdugo tiene en cuenta los riesgos de naturaleza socioeconómica, técnica y la vulnerabilidad, distinguiendo entre las causas externas (aquellas que nacen fuera del país que compra energía, por lo tanto tienen que ver con la situación de las naciones vendedoras y de transporte) y las internas (las que nacen en el propio territorio, por lo que influye la situación del propio Estado importador). Dentro de la política de la energía europea el pilar de la seguridad energética es el que históricamente se ha unido con la dimensión exterior de los riesgos energéticos ${ }^{10}$. Uno de los objetivos de esta investigación es analizar la dimensión exterior de dicha seguridad de los Estados miembros de la UE-28. Al mismo tiempo, ya que estos autores admiten que los riesgos técnicos son poco significativos a la hora de reseñar la seguridad energética no se tendrán en cuenta en su cuantificación, sin tener que verse perjudicado el resultado (Rodríguez y García-Verdugo, 2012: 233).

\section{Gráfico 1. Dimensiones de la seguridad de abastecimiento energético}

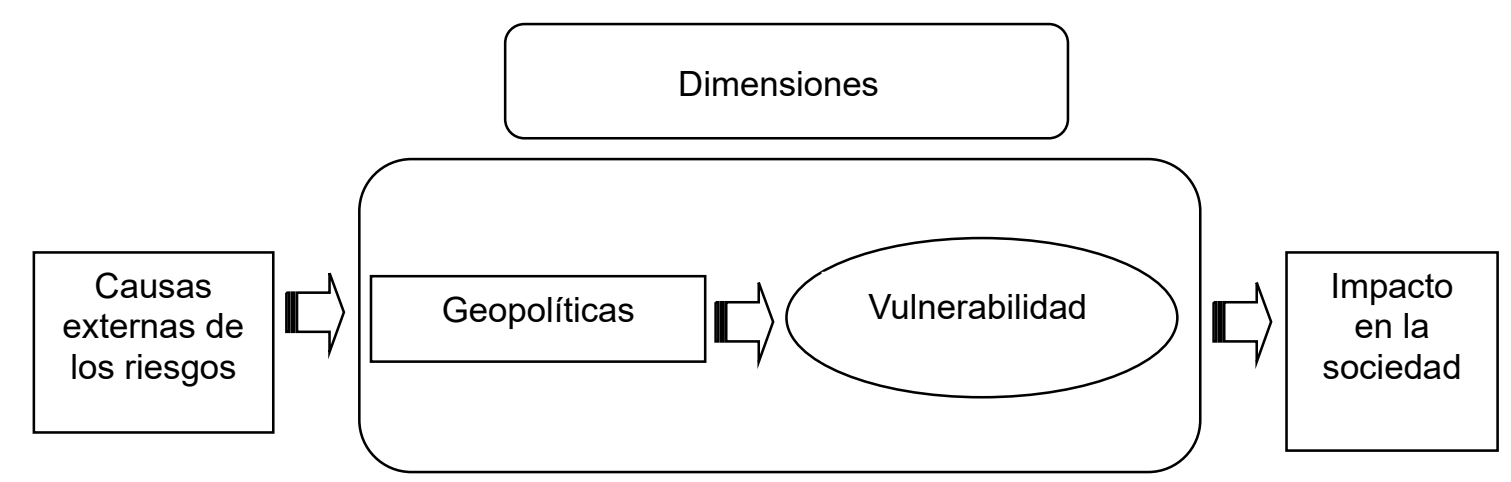

Fuente: Adaptado de Rodríguez y García-Verdugo (2012)

La propuesta de las dimensiones que componen la seguridad de abastecimiento energético se recoge en el gráfico 1 :

\footnotetext{
${ }^{10}$ La dimensión exterior de los riesgos está compuesta por todos los elementos enlazados con la dependencia de las importaciones energéticas, la geopolítica, el tránsito internacional y cuestiones técnicas (Checchi et al., 2009: 4). Muñoz (2012: 296) argumenta que la noción es más extensa, ya que engloba todos los riesgos primarios que tienen lugar en el extranjero.
} 
Fernández, Ana; Rodríguez, Laura. Seguridad de abastecimiento energético en la Unión Europea en el contexto del conflicto gasista ruso-ucraniano.

- Geopolítica11. Está integrada por factores económicos, políticos y sociales, y en este caso también los conectados con el sector de la energía como es la presencia de reservas de recursos energéticos (García-Verdugo y San Martín, 2011: 134). Los vínculos geopolíticos que se derivan de la distribución geográfica de los recursos energéticos se pueden trazar como un sistema enredado de productores interdependientes, consumidores y regiones de tránsito (Escribano y García-Verdugo, 2011: 26).

- Vulnerabilidad. La dimensión precedente se relaciona directamente con los riesgos denominados primarios por García-Verdugo y San Martín (2011), pero es necesario incorporar una segunda dimensión asociada al concepto: la vulnerabilidad, que a la hora de estudiar el riesgo energético estos autores introducen junto con la evolución de los precios de la energía como vectores que confluyen en la determinación del riesgo energético global de una economía. Los precios no van a ser incluidos en nuestro análisis, por lo que nos centraremos en el concepto de vulnerabilidad que es una peculiaridad de los sistemas económicos que condiciona el efecto ante los riesgos secundarios (Marín et al., 2012: 76) y está vinculada con la interrupción esporádica del suministro o con el aumento de precios (esta investigación solamente hace una reflexión sobre los cortes de aprovisionamiento). Adicionalmente la vulnerabilidad de un Estado disminuye cuanto más grande es su flexibilidad para adecuar su consumo a las diferentes eventualidades (Avedillo y Muñoz, 2007: 44) y una menor vulnerabilidad conduce a una mayor seguridad energética. A su vez la vulnerabilidad puede ser explorada desde el corto plazo, cuando las dificultades de suministro energético se solucionan brevemente y desde el largo plazo, cuando los contratiempos son estructurales y no se pueden solventar rápidamente (Rodríguez y García-Verdugo, 2012: 233). El horizonte temporal contemplado en este artículo es la vulnerabilidad a largo plazo por ser ésta la que afecta verdaderamente en el nivel de seguridad de suministro de una nación. En cuanto a las variables que determinan la vulnerabilidad a largo plazo destacamos: la dependencia energética externa ${ }^{12}$ y la conectividad ${ }^{13}$.

\section{LA SEGURIDAD DE ABASTECIMIENTO ENERGÉTICO EN LA UE-28}

La seguridad energética transcendental para los países importadores y por lo tanto para los de la UE-28 es la seguridad de abastecimiento (Rodríguez y GarcíaVerdugo, 2012: 231). La energía es vital en la vida diaria de la UE. De hecho fue uno de los orígenes que condujeron a la integración europea donde las primeras comunidades (la Comunidad Europea del Carbón y del Acero -CECA- y la

\footnotetext{
${ }^{11}$ Metodología multidisciplinar que examina la influencia del espacio geográfico sobre los Estados y su política (López y Del Pozo, 1999: 283).

${ }^{12}$ La dependencia energética se centra en el nivel de control sobre las fuentes de abastecimiento de energía de un territorio. Las variables de dependencia se relacionan con la autosuficiencia en el suministro energético, la diversificación de orígenes y las relaciones de interdependencia entre el lugar importador y exportador (Avedillo y Muñoz, 2007: 44). Según la Oficina de Estadística de la Comisión Europea la dependencia energética plasma el grado en que una economía depende de las importaciones para satisfacer sus necesidades energéticas. De esta expresión se deduce que si las importaciones están diversificadas el riesgo de interrupción de suministro se reducirá y el nivel de seguridad de abastecimiento aumentará.

${ }^{13}$ El valor o utilidad de una red depende del número de conexiones y el alcance de la propia red. En general, cuanto más interconectado está un sistema energético más seguridad del suministro proporciona y más flexibilidad otorga a la hora de diversificar rutas y suministradores, sobre todo en el caso del gas por la exigencia de unas infraestructuras específicas.
} 
Fernández, Ana; Rodríguez, Laura. Seguridad de abastecimiento energético en la Unión Europea en el contexto del conflicto gasista ruso-ucraniano.

Comunidad Europea de la Energía Atómica -EURATOM-) se encargaron de gestionar el carbón y la energía nuclear. Sin embargo, en esta fase inicial los Tratados se caracterizaron por una carencia de competencias en este ámbito. A finales de la década de los noventa comenzaron las reformas comunitarias del sector del gas, las cuales quedaron reflejadas en el Libro Verde del año 2000. Estas medidas defendieron la idea de que el funcionamiento de los mercados avalaría el abastecimiento, puesto que los mercados energéticos liberalizados y la gradual interdependencia económica de las naciones hacen que la seguridad energética sea una responsabilidad de los actores del mercado: empresas, consumidores y entidades reguladoras. Al mismo tiempo se abordó la liberalización del sector eléctrico con el fin de ampliar el marco de actividad de las compañías privadas en ambos mercados (los dos sectores están relacionados por varias razones: el ascendente consumo del gas en la UE es debido en gran medida a su superior contribución al mix eléctrico y un gran número de sociedades trabajan conjuntamente en el sector del gas y la electricidad (Palazuelos, 2008: 96-116)).

Posteriormente estas medidas avanzan con el Tratado Constitucional, consolidado por el Tratado de Lisboa en diciembre de 2007 (Zapater, 2009: 58) tras la crisis de suministro energético ocasionada por Rusia. Este último Tratado en su artículo 176 establece la seguridad de abastecimiento energético, junto con la garantía del funcionamiento del mercado de la energía, el fomento de la interconexión de las redes energéticas y de la eficiencia energética, el ahorro energético, así como el desarrollo de energías nuevas y renovables, una de las metas de la política energética europea (Diario Oficial de la Unión Europea, 2007: 88). A pesar de los intentos y el paso de los años no se ha conseguido crear una institución con jurisdicción efectiva en el mercado del gas.

Todos los países miembros se ven afectados por el asunto de la seguridad del abastecimiento energético, aunque es cierto que algunos son más vulnerables que otros, particularmente las zonas que se encuentran menos conectadas e integradas, como el Báltico y Europa Oriental. La preocupación más urgente relacionada con la materia objeto de estudio es la gran dependencia de un único proveedor externo, en especial en lo concerniente al gas (European Commission, 2014a: 2).

La mayoría de los Estados miembros de la UE comparten las mismas características: la dependencia y vulnerabilidad energética frente a fuentes externas, que suscita seguridad en el caso de Noruega e inseguridad con Rusia, Argelia, Asia Central o el Golfo Pérsico. En este escenario el sistema energético interno contemporáneo de la UE-28 no es completamente seguro para estimular un crecimiento sostenido de la economía. Este territorio está consumiendo cada vez más energía e importa cada vez más productos energéticos. Como resultado, su tasa de dependencia energética ha aumentado en 3,2 puntos porcentuales desde 2004 hasta 2014 (tabla 1). Esta situación se debe a unas mayores tasas de dependencia energética de todos los productos. Precisamente, tanto la tasa de dependencia de combustibles sólidos, como la del petróleo crudo y la del gas natural fueron más elevadas al final de la etapa estudiada (concretamente 7,4 puntos porcentuales mayor en el caso de los combustibles sólidos, 7,7 puntos porcentuales en el petróleo crudo y 13,6 puntos porcentuales en el gas natural, lo que pone de manifiesto la hegemonía de esta última). Asimismo, tal y como muestra la tabla 1, la UE-28 importó en el año 2014 el 
Fernández, Ana; Rodríguez, Laura. Seguridad de abastecimiento energético en la Unión Europea en el contexto del conflicto gasista ruso-ucraniano.

$53,4 \%$ de la energía que consumió (la dependencia de las entradas afectó al crudo en casi un $90 \%$, al gas natural en un $67,2 \%$ y en último lugar a los combustibles sólidos en un $45,6 \%$ ).

Tabla 1. Tasa de dependencia energética de la UE-28, 2004-2014 (\% de las importaciones netas del consumo interior bruto y bunkers ${ }^{14}$, en toneladas equivalentes de petróleo)

\begin{tabular}{|c|c|c|}
\hline & 2004 & 2014 \\
\hline Todos los productos & 50,2 & 53,4 \\
\hline Combustibles sólidos & 38,2 & 45,6 \\
\hline Petróleo crudo & 79,7 & 87,4 \\
\hline Gas natural & 53,6 & 67,2 \\
\hline
\end{tabular}

Fuente: Eurostat,

http://ec.europa.eu/eurostat/tgm/refreshTableAction.do?tab=table\&plugin=1\&p code $=$ tsdcc310\&language $=e n, 06 / 04 / 2016$

A finales del año 2010 el Parlamento Europeo expuso en unos de sus reglamentos que el gas natural constituye un elemento esencial del suministro energético de la UE, ya que representa una cuarta parte del abastecimiento de energía primaria, aportando a la producción de electricidad, calefacción, materias primas para las industrias y combustible para el transporte. Asimismo puso de manifiesto que la entrada y el consumo de gas en tierras europeas se ha incrementado a gran velocidad en la última década, a la vez que la producción de energía primaria ha descendido15, dando lugar a una gran dependencia de las importaciones y a la obligación de plantear medidas vinculadas con la seguridad de abastecimiento de gas. Igualmente, como consecuencia de la insuficiencia de infraestructuras de enlace algunos países constituyen "islas gasistas" (Parlamento Europeo, 2010: 1). Por otro lado, la producción nacional de gas representa el $34 \%$ del consumo siendo los Países Bajos, Reino Unido, Alemania y Rumania los mayores productores con un $43 \%, 26 \%, 7 \%$ y $6,5 \%$ respectivamente (European Commission 2014d: 1 ).

El acceso de la UE a la oferta de gas natural es esencialmente un aspecto regional (Correljé y Van der Linde, 2006: 534). La inquietud sobre este recurso por parte de la UE es que las vías de transporte se disponen por canales en vez de por el mar, como ocurre con el petróleo. En consecuencia varios países miembros dependen de un proveedor exclusivo (sobre todo la zona del este de Europa). En suma, sus particularidades técnicas, los contratos de importación de larga duración y el hecho de que la mayoría de Estados carezcan de producción, aminoran el número de compañías que intervienen en este sector, lo que ha dado lugar a oligopolios privados (o públicos en algunos lugares) que intervienen en uno o varios mercados nacionales con escasa regulación de las autoridades públicas europeas (Palazuelos, 2008: 120-121).

\footnotetext{
${ }^{14}$ Este término comprende todos los productos petrolíferos sujetos a derechos cargados a bordo de un buque para el consumo de éste (http://epp.eurostat.ec.europa.eu/statistics_explained/index.php/Glossary:Bunkers).

${ }^{15}$ Según datos de Eurostat en el intervalo de tiempo comprendido entre 2004 y 2014, la producción de energía primaria en la UE-28 disminuyó un 17,16\%. Este descenso tiene que ver con al menos dos factores: la crisis económica y financiera de 2008 y el agotamiento de los suministros de materias primas, teniendo en cuenta que los recursos naturales son limitados.
} 
Fernández, Ana; Rodríguez, Laura. Seguridad de abastecimiento energético en la Unión Europea en el contexto del conflicto gasista ruso-ucraniano.

La situación actual en Ucrania y el posible riesgo de una parada del suministro de gas ruso a la UE delatan la carencia de una política energética común. En los últimos tiempos se ha progresado en el refuerzo de la seguridad de abastecimiento de la Unión en materia de aprovisionamiento de gas y el descenso del número de países que dependen únicamente de un solo distribuidor (European Commission 2014a: 2). Sin embargo, a pesar de la mejora de infraestructuras y diversificación de suministradores, la UE aún es vulnerable frente a trastornos energéticos externos como muestra su elevada tasa de dependencia energética.

La tabla 2 revela la gran dependencia de la UE-28 que existe respecto de Rusia en referencia a las compras de gas, de combustibles sólidos y de petróleo crudo. En este sentido mientras que en 2003 la mayor parte de las importaciones de combustibles sólidos se derivaron de Sudáfrica y Australia, en 2013 provenían de Rusia, Colombia y EE.UU. Por otro lado gran parte de las importaciones de petróleo crudo en 2013 procedieron de Rusia y Noruega (aunque Noruega ha visto decrecer su importancia en comparación con 2003).

Tabla 2. Principal origen de las importaciones de energía primaria de la UE-28, 20032013 (\% de las importaciones netas)

\begin{tabular}{|c|c|c|}
\hline \multirow[t]{2}{*}{ Combustibles sólidos } & & \\
\hline & 2003 & 2013 \\
\hline Rusia & 13,2 & 28,8 \\
\hline Colombia & 11,7 & 22,4 \\
\hline Estados Unidos & 6,6 & 21,8 \\
\hline Otros & 10,1 & 5,9 \\
\hline \multicolumn{3}{|l|}{ Petróleo crudo } \\
\hline & 2003 & 2013 \\
\hline Rusia & 31,2 & 33,5 \\
\hline Noruega & 19,1 & 11,7 \\
\hline Otros & 17,7 & 14,4 \\
\hline \multicolumn{3}{|l|}{ Gas natural } \\
\hline & 2003 & 2013 \\
\hline Rusia & 44,1 & 39,0 \\
\hline Noruega & 25,5 & 29,5 \\
\hline Otros & 6,5 & 6,9 \\
\hline
\end{tabular}

Fuente: Eurostat, http://ec.europa.eu/eurostat/statisticsexplained/index.php/Energy_production_and_imports, 06/04/2016

A pesar de que las compras de gas a Rusia han ido mermando paulatinamente en la década investigada este país es el principal proveedor de la Unión, seguido de cerca por Noruega. En el año 2013 la UE-28 importó el 39\% de su gas de Rusia. La UE está actualmente mejor dotada que en 2006 y 2009 para hacer frente a las disputas mencionadas, pero una lucha prolongada entre Rusia y Ucrania puede tener costes económicos significativos para la UE (Escribano, 2014: 1).

Cabe destacar que en este contexto hay una doble dimensión de la vulnerabilidad ligada a la dependencia: la del consumidor, el cual puede dejar de ser suministrado, y la del productor, quien puede perder o ver impedida la exportación de sus mercancías. En el caso de Rusia gran parte de sus ventas a la UE se hacen por 
Fernández, Ana; Rodríguez, Laura. Seguridad de abastecimiento energético en la Unión Europea en el contexto del conflicto gasista ruso-ucraniano.

tuberías que pasan por otros territorios, entre ellos Ucrania y Bielorrusia. El inconveniente del tránsito se ha dejado ver a la hora de exportar petróleo y gas de las regiones rusas a través de tierras ucranianas (Sánchez, 2008: 103). Como se ha aludido anteriormente aproximadamente el 53\%16 del gas ruso que se dirige a la UE pasa por regiones ucranianas. En consecuencia se presenta el dilema de la vulnerabilidad de tránsito para la UE y para Rusia. En este sentido es necesario aclarar que es más adecuado hablar de una interdependencia que de una dependencia. Siguiendo a De la Cámara (2009: 5) el continente europeo necesita a Rusia y la Unión Europea es el socio que Rusia precisa para el fomento de una base económica que dependa de más productos que el gas, el crudo, las manufacturas metálicas y los minerales. En definitiva, Rusia y Europa dependen unos de otros, como el proveedor depende del comprador y viceversa (Thumann, 2006: 13).

El análisis por Estados pone de manifiesto diferencias apreciables dentro de la UE28 (tabla 3). Dentro del período analizado (2002-2012) se pueden distinguir cuatro grupos distintos: un grupo que abarca los países con dependencia total, estos son, Bulgaria, Estonia, Eslovaquia, Letonia, Lituania y Finlandia; otro grupo que comprende los países miembros con dependencia alta (importaciones de gas ruso mayores al 40\%) y son, por orden de vinculación: Rumania, Hungría, Croacia, República Checa, Grecia, Austria, Eslovenia, y Polonia; otro grupo con dependencia intermedia en torno al 30\% (media de la UE-28) comprendido por Alemania e Italia y por último hay un grupo de naciones con dependencia baja o nula como son Bélgica, Dinamarca, Irlanda, España, Francia, Luxemburgo, Malta, Países Bajos, Portugal, Suecia y Reino Unido.

Tabla 3. Importaciones de gas de la UE-28, 2002-2012 (terajulios)

\begin{tabular}{|c|c|c|c|}
\hline & \multicolumn{3}{|c|}{ Media anual para 2002-2012 } \\
\cline { 1 - 3 } & $\begin{array}{c}\text { Importaciones } \\
\text { totales }\end{array}$ & $\begin{array}{c}\text { Importaciones } \\
\text { desde Rusia }\end{array}$ & $\begin{array}{c}\text { \% Importaciones } \\
\text { de Rusia sobre } \\
\text { total importaciones }\end{array}$ \\
\hline UE-28 & 167.187 .041 & 51.617 .649 & 30,87 \\
\hline Zona euro & 136.443 .823 & 38.288 .739 & 28,06 \\
\hline Alemania & 38.100 .717 & 14.993 .851 & 39,35 \\
\hline Austria & 4.444 .215 & 2.878 .668 & 64,77 \\
\hline Bélgica & 8.051 .191 & 182.934 & 2,27 \\
\hline Bulgaria & 1.229 .816 & 1.229 .816 & 100,00 \\
\hline Croacia & 460.640 & 368.816 & 80,07 \\
\hline Dinamarca & 77.444 & 0 & 0,00 \\
\hline Eslovaquia & 2.683 .689 & 2.680 .184 & 99,87 \\
\hline Eslovenia & 434.985 & 228.486 & 52,53 \\
\hline España & 14.816 .754 & 0 & 0,00 \\
\hline Estonia & 342.775 & 342.775 & 100,00 \\
\hline Finlandia & 1.881 .954 & 1.881 .954 & 100,00 \\
\hline Francia & 20.584 .137 & 3.486 .510 & 16,94 \\
\hline Grecia & 1.473 .126 & 992.364 & 67,36 \\
\hline Hungría & 4.382 .889 & 3.715 .798 & 84,78 \\
\hline Irlanda & 1.864 .099 & 0 & 0,00 \\
\hline
\end{tabular}

${ }^{16}$ El dato se refiere a 2014.

Papeles de Europa 
Fernández, Ana; Rodríguez, Laura. Seguridad de abastecimiento energético en la Unión Europea en el contexto del conflicto gasista ruso-ucraniano.

\begin{tabular}{|c|c|c|c|}
\hline Italia & 29.503 .434 & 8.793 .518 & 29,81 \\
\hline Letonia & 686.356 & 686.356 & 100,00 \\
\hline Lituania & 1.273 .172 & 1.273 .172 & 100,00 \\
\hline Luxemburgo & 576.072 & 73.546 & 12,77 \\
\hline Malta & 0 & 0 & 0,00 \\
\hline Países Bajos & 9.076 .197 & 1.067 .593 & 11,76 \\
\hline Polonia & 4.378 .912 & 2.197 .495 & 50,18 \\
\hline Portugal & 1.924 .122 & 0 & 0,00 \\
\hline Reino Unido & 13.029 .496 & 0 & 0,00 \\
\hline República Checa & 3.730 .153 & 2.954 .947 & 79,22 \\
\hline Rumania & 1.676 .156 & 1.588 .866 & 94,79 \\
\hline Suecia & 504.540 & 0 & 0,00 \\
\hline
\end{tabular}

Nota: La lista es para aquellos países que importan gas.

Fuente: Elaboración propia con datos de Eurostat,

http://appsso.eurostat.ec.europa.eu/nui/submitViewTableAction.do, 22/10/2014

Cada país miembro posee su sistema energético y escoge su propia combinación energética, lo que puede ocasionar discrepancias entre los Estados. La alternativa realizada por cada uno de ellos tendrá un impacto en la seguridad de abastecimiento del resto y de la UE en su conjunto (European Commission, 2006: 9). Estas diferencias dificultan la creación de una política energética conjunta.

\section{CUANTIFICACIÓN}

En la actualidad se puede apreciar una amplia literatura sobre la cuantificación de la seguridad de abastecimiento energético. Generalmente la medición se puede llevar a cabo por medio de indicadores simples o compuestos (Sovacool y Mukherjee, 2011: 5346). Los primeros se refieren a una única dimensión o magnitud y los segundos a varios conceptos multidimensionales.

Algunos trabajos cuantifican la seguridad energética mediante índices compuestos que combinan distintos tipos de energía (por ejemplo Avedillo y Muñoz, 2007 y Rodríguez y García-Verdugo, 2012). Otros estudios como el de Muñoz (2012) realizan una medición de los riesgos energéticos de la seguridad del suministro. Asimismo diversas instituciones energéticas como el Centro de Investigación de la energía Asia Pacífico y la Agencia Internacional de la Energía han hecho hincapié dentro de este ámbito. Todas las investigaciones son útiles y provechosas, sin embargo, la mayoría de ellas ofrecen una visión conjunta de la seguridad de abastecimiento energético. A todo esto hay que añadir que pocos indicadores la evalúan a través del tiempo (Ren y Sovacool, 2014: 840). Por todo lo anterior este artículo presenta un índice sintético relativo únicamente al gas natural dentro del contexto de las nombradas crisis del gas (2005-2010) con el propósito de evaluar el cambio de la seguridad de suministro energético de los Estados miembros con dependencia alta y total del gas ruso según el apartado previo. Vale la pena subrayar el análisis de Cohen et al. (2011), que elaboraron un índice de diversificación global para el petróleo y el gas natural, y el de Le Coq y Paltseva (2009) quienes construyeron un índice separado para los tres tipos de energía primaria (petróleo, gas y carbón) tratándose de un índice desagregado que tiene el fin de medir el riesgo energético a corto plazo. 
Fernández, Ana; Rodríguez, Laura. Seguridad de abastecimiento energético en la Unión Europea en el contexto del conflicto gasista ruso-ucraniano.

De esta manera siguiendo la exposición del apartado 2.2 las dos dimensiones principales para cuantificar la seguridad de abastecimiento conforme a la taxonomía causal del riesgo energético son la geopolítica y la vulnerabilidad. Ambas se medirán a partir de indicadores simples que forman parte del denominado "Índice Ponderado de Seguridad Energética". Ya que no existe un único método aceptado para elaborar dicho indicador el propio analista debe decidir los indicadores iniciales, la manera de agruparlos, el criterio de ponderación de cada indicador y el modo de agregación (Pérez et al., 2008: 3). Estos hechos podrían ser considerados como un inconveniente de este tipo de índices, sin embargo, más bien se valoran como desafíos metodológicos que se deben resolver (Saturno, 2004: 408). Por el contrario cuentan con grandes ventajas como son, entre otras: la facilidad de interpretación y la capacidad para sintetizar problemas complejos y multidimensionales (Saisana y Tarantola, 2002: 5). De acuerdo con Sovacool (2012: 835-836) existe una necesidad de crear índices de seguridad energética por cuatro razones esenciales: la seguridad de abastecimiento es un concepto multidimensional; con la creación de un método sistemático para medir el rendimiento de la seguridad de aprovisionamiento se puede contribuir en las políticas energéticas y en la creación de capacidad institucional; un índice de seguridad energética permite observar la evolución a través del tiempo y por último ayuda a determinar las ventajas y desventajas dentro de las diversas dimensiones de la seguridad de abastecimiento y de los sectores en los cuales se debe mejorar.

Gráfico 2. Composición y ponderación del IPSE para el gas

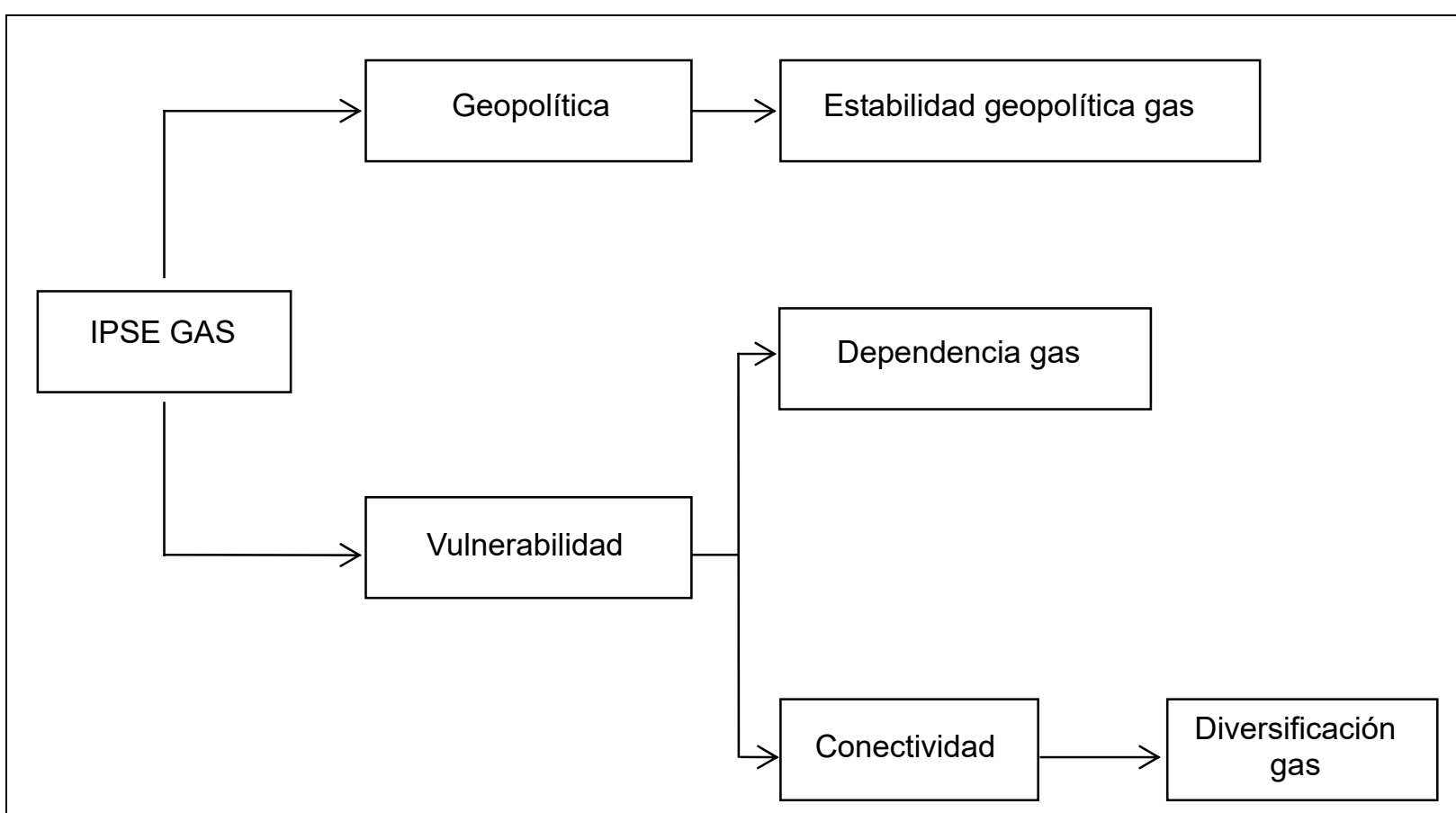

Nota: Se hace un cambio variable para confeccionar el IPSE. Cada indicador tiene la misma ponderación $(w t=1 / n)$

Fuente: Elaboración propia 
Fernández, Ana; Rodríguez, Laura. Seguridad de abastecimiento energético en la Unión Europea en el contexto del conflicto gasista ruso-ucraniano.

En esta investigación se ha usado un único método de agregación: cada dimensión de la seguridad energética se pondera al $50 \%$ al considerar que poseen la misma relevancia. A su vez se utiliza el mismo criterio para los dos indicadores simples que forman parte de la dimensión de la vulnerabilidad (gráfico 2).

De conformidad con la literatura existente existen varios indicadores que permiten cuantificar cada una de las dimensiones seleccionadas. En el caso de la geopolítica se usará un único indicador: el Índice de Riesgo Socioeconómico, por sus siglas en inglés SERI ${ }^{17}$ (García-Verdugo y San Martín, 2011) de las importaciones de gas. Dicho índice estima cuantitativamente los riesgos socioeconómicos. Según Marín et al. (2012: 73) son aquellos que engloban todos los riesgos procedentes de la organización de la actividad humana en sus primordiales manifestaciones: la económica, la política, la social y las variables del sector energético vinculadas a problemas de suministro energético. Dicho índice ha sido confeccionado por el Grupo de Investigación de la Universidad Nacional de Educación a Distancia "Economía Política Internacional y Energía" y el Instituto Klein de la Universidad Autónoma de Madrid en el marco del Proyecto REACCESS ${ }^{18}$.

La segunda dimensión elegida (la vulnerabilidad a largo plazo) es más compleja de evaluar, ya que además de depender del tipo de energía de que se trate posee un elemento de subjetividad más elevado. En este artículo se estimará a partir de las dos subdimensiones citadas previamente: la dependencia energética exterior y la conectividad. La dependencia energética es una de las medidas más utilizadas para valorar la seguridad energética (Kruyt et al., 2009: 2168). En este caso se usará la dependencia energética relativa a las importaciones de gas (obtenida del cociente de las importaciones netas de gas y la suma del consumo interior bruto de dicho recurso más los bunkers). Por otra parte, la conectividad se medirá a través de la diversificación de gas mediante el índice de concentración de proveedores ${ }^{19}$ específico para el aprovisionamiento de dicha fuente energética elaborado por la Comisión Europea en su último estudio en profundidad sobre la seguridad

\footnotetext{
${ }^{17}$ Socioeconomic Energy Risk Index (SERI) se calcula a partir de un análisis factorial que permite calcular el riesgo socioeconómico de un conjunto de países en un rango de $[0,100]$, donde 0 significa ausencia de riesgo y 100 riesgo máximo. Se asumen una serie de supuestos imprescindibles para realizar el cálculo necesario y como punto de partida se selecciona un conjunto selecto y reducido de variables que representen los cuatro vectores que forman el SERI: Económico, Energético, Político y Social. Para más detalle véase García-Verdugo et al. (2011: 144-169).

${ }^{18}$ El objetivo principal del Proyecto REACCESS (Risk of Energy Availability: Common Corridors for Europe's Supply Security) es la construcción de herramientas adecuadas para el análisis del escenario de importación de energía de la UE-27, capaz de tener en cuenta al mismo tiempo los aspectos técnicos, económicos y ambientales de los principales corredores de energía, para todos los productos energéticos y de infraestructuras (http://reaccess.epu.ntua.gr/).

${ }^{19}$ El Supplier Concentration Index (SCI) es una medida de la diversificación y la exposición de los países a los proveedores de fuera de la UE y del Espacio Económico Europeo (EEE). Se calcula como la suma de los cuadrados del cociente de las importaciones netas positivas de un socio para un país importador y el consumo interior bruto de ese combustible en el país importador. El valor del índice se encuentra entre 0 y 100 . Los valores más bajos del SCI indican diversificación más grande y por lo tanto el riesgo es más bajo y la seguridad energética más alta. Los valores más altos advierten que todo el consumo proviene de un sólo proveedor. Esta medida es muy útil para los países que importan grandes cantidades de gas de fuera del EEE.
} 
Fernández, Ana; Rodríguez, Laura. Seguridad de abastecimiento energético en la Unión Europea en el contexto del conflicto gasista ruso-ucraniano.

energética y que se basa en el índice de Herfindahl-Hirschmann ${ }^{20}$ (European Commission 2014c: 178).

Ya que la estabilidad geopolítica de los proveedores de gas, la dependencia del gas y la concentración de las importaciones de este recurso poseen una relación negativa con la seguridad es necesario hacer un cambio de variable para que representen una medida de la seguridad de abastecimiento energético, es decir, se deben transformar para que tengan un nexo positivo con ella. De esta manera se obtendrían los valores de las subdimensiones de estudio, mostrándose en la tabla 4.

Tabla 4. Subdimensiones del IPSE, 2005-2010 (\%)

\begin{tabular}{|l|c|c|c|c|c|c|}
\hline & \multicolumn{2}{|c|}{ Geopolítica } & \multicolumn{2}{c|}{$\begin{array}{c}\text { Dependecia } \\
\text { energética exterior }\end{array}$} & \multicolumn{2}{c|}{ Conectividad } \\
\hline & 2005 & 2010 & 2005 & 2010 & 2005 & 2010 \\
\hline UE-28 & 68,2 & 68,0 & 42,9 & 37,9 & 58,4 & 65,6 \\
\hline Austria & 73,8 & 73,7 & 12,3 & 25,6 & 51,0 & 38,2 \\
\hline Bulgaria & 69,9 & 62,2 & 12,3 & 7,4 & 23,2 & 14,2 \\
\hline Croacia & 60,9 & 61,8 & 76,3 & 81,9 & 84,7 & 89,6 \\
\hline Eslovaquia & 59,2 & 63,7 & 2,5 & 0,1 & $-5,6$ & 0,2 \\
\hline Eslovenia & 61,2 & 62,1 & 0,4 & 0,7 & 48,7 & 67,5 \\
\hline Estonia & 60,9 & 61,5 & 0 & 0 & 0 & 0 \\
\hline Finlandia & 63,9 & 62,0 & 0 & 0 & 0 & 0 \\
\hline Grecia & 59,1 & 58,8 & 0,9 & 0,1 & 28,7 & 60,2 \\
\hline Hungría & 60,4 & 62,5 & 18,9 & 21,3 & 63,2 & 42,5 \\
\hline Letonia & 60,9 & 60,9 & $-5,6$ & 38,2 & $-11,5$ & 61,8 \\
\hline Lituania & 60,9 & 60,9 & $-0,6$ & 0,3 & $-1,3$ & 0,6 \\
\hline Polonia & 61,7 & 58,7 & 30,3 & 30,7 & 77,3 & 61,2 \\
\hline R. Checa & 69,3 & 69,9 & 2,2 & 15,2 & 43,6 & 42,7 \\
\hline Rumanía & 59,7 & 61,3 & 69,9 & 83,2 & 90,9 & 97,3 \\
\hline
\end{tabular}

Fuente: Elaboración propia con datos de Rodríguez y García-Verdugo (2012), European Commission, 2014c y Eurostat,

http://epp.eurostat.ec.europa.eu/tgm/refreshTableAction.do;jsessionid=9ea7d07e30de1d9 072258aaf4450a8d78f7bfb686bf4.e34OaN8Pc3mMc40Lc3aMaNyTbN8Te0?tab=table\&pl ugin $=1 \&$ pcode $=$ tsdcc310\&language $=$ en $(21 / 11 / 2014)$

\footnotetext{
${ }^{20}$ El índice de Herfindahl-Hirschman (IHH) estándar se utiliza en la literatura de organización industrial para evaluar la concentración del mercado. Es igual a la suma de los cuadrados de la cuota de mercado de cada participante y se basa en el origen geográfico de las fuentes energéticas (Le Coq y Paltseva 2009: 4475).
}

Papeles de Europa 
Fernández, Ana; Rodríguez, Laura. Seguridad de abastecimiento energético en la Unión Europea en el contexto del conflicto gasista ruso-ucraniano.

Tras calcular el índice geopolítico y el índice de vulnerabilidad de acuerdo con las ponderaciones mencionadas se obtendría la evolución de los valores del IPSE para el gas de los Estados miembros más dependientes de Rusia, ligada al promedio de la Unión (tabla 5) dentro del ciclo examinado. El valor de este planteamiento es su capacidad para enseñar cómo el grado de seguridad energética cambia a través del tiempo.

Tabla 5. Índice Ponderado de Seguridad Energética para el gas, 2005-2010 (\%)

\begin{tabular}{|l|c|c|c|c|c|c|c|}
\hline & \multicolumn{2}{|c|}{ Geopolítica } & \multicolumn{2}{c|}{ Vulnerabilidad } & \multicolumn{2}{c|}{ IPSE GAS } & Variación \\
\hline & 2005 & 2010 & 2005 & 2010 & 2005 & 2010 & $\begin{array}{c}\Delta 2005-2010 \\
(\%)\end{array}$ \\
\hline UE-28 & 68,2 & 68,0 & 52,6 & 54,9 & 60,3 & 61,4 & 1,8 \\
\hline Austria & 73,8 & 73,7 & 49,8 & 45,6 & 61,8 & 59,7 & $-3,5$ \\
\hline Bulgaria & 69,9 & 62,2 & 40,7 & 37,7 & 55,3 & 49,9 & $-9,7$ \\
\hline Croacia & 60,9 & 61,8 & 61,0 & 62,6 & 60,9 & 62,2 & 2,1 \\
\hline Eslovaquia & 59,2 & 63,7 & 31,2 & 33,1 & 45,2 & 48,4 & 7,1 \\
\hline Eslovenia & 61,2 & 62,1 & 49,1 & 55,3 & 55,1 & 58,7 & 6,4 \\
\hline Estonia & 60,9 & 61,5 & 33,0 & 33,0 & 47,0 & 47,3 & 0,6 \\
\hline Finlandia & 63,9 & 62,0 & 33,0 & 33,0 & 48,5 & 47,5 & $-2,0$ \\
\hline Grecia & 59,1 & 58,8 & 42,5 & 52,9 & 50,8 & 55,8 & 9,9 \\
\hline Hungría & 60,4 & 62,5 & 53,9 & 47,0 & 57,1 & 54,8 & $-4,1$ \\
\hline Letonia & 60,9 & 60,9 & 29,2 & 53,4 & 45,1 & 57,1 & 26,8 \\
\hline Lituania & 60,9 & 60,9 & 32,6 & 33,2 & 46,7 & 47,0 & 0,7 \\
\hline Polonia & 61,7 & 58,7 & 58,5 & 53,2 & 60,1 & 55,9 & $-6,9$ \\
\hline R. Checa & 69,3 & 69,9 & 47,4 & 47,1 & 58,3 & 58,5 & 0,3 \\
\hline Rumanía & 59,7 & 61,3 & 63,0 & 65,1 & 61,3 & 63,2 & 3,0 \\
\hline
\end{tabular}

Fuente: Elaboración propia

Si se observa la evolución del IPSE del gas de la UE-28 se verifica que la seguridad energética ha mejorado casi un $2 \%$ en la fase analizada, lo que representa un avance muy escaso.

Lituania fue la peor región en cuanto a la seguridad del suministro en 2010 seguida muy de cerca por Estonia y Finlandia. Esto se debe a que se encuentran por debajo de la media de la UE-28 en todas las dimensiones y subdimensiones exploradas: no disponen de control sobre las fuentes de abastecimiento de gas (lo que conduce a acentuar su dependencia) y su grado de conectividad es nulo. En cambio Croacia y Rumania son los mejores posicionados en el ranking del IPSE del gas con valores 
Fernández, Ana; Rodríguez, Laura. Seguridad de abastecimiento energético en la Unión Europea en el contexto del conflicto gasista ruso-ucraniano.

similares en todas las variables contempladas. Ambos disponen de un dominio de las importaciones (en el caso de Rumania por ser uno de los mayores productores de gas de la Unión como se ha mencionado anteriormente) y una diversificación de aprovisionadores de gas superior a la media, ahora bien, las estabilidades geopolíticas de sus entradas de gas son inferiores al promedio.

Los países con plena y exclusiva dependencia de las importaciones de gas ruso (Bulgaria, Estonia, Eslovaquia, Letonia, Lituania y Finlandia) tienen en común el bajo valor del IPSE durante 2005 y 2010 (salvo Letonia en este último espacio de tiempo y Bulgaria en 2005) como resultado de los datos de la vulnerabilidad (despuntando su considerable dependencia exterior -ocasionada por el bajo control de las fuentesy su escasa conectividad) y la estabilidad geopolítica de las compras de gas por debajo de la media de la Unión, sobre todo en la primera. Avedillo y Muñoz (2007: 45) hacen alusión a que las zonas de Europa del Este no se ven beneficiadas de la estabilidad geopolítica de los suministradores porque compran grandes volúmenes a Rusia.

Una conclusión sustancial de la tabla 5 es que la mayoría de territorios estudiados (excepto Austria, Bulgaria, Finlandia, Hungría y Polonia) han ampliado su nivel de seguridad energética entre 2005 y 2010 , lo que se deriva en una rebaja del riesgo de corte de suministro ante una nueva crisis. Resulta llamativo el progreso de Letonia sobre todo si se observa el cuantioso aumento de los valores del indicador de la vulnerabilidad. Dichos valores se deben al uso de almacenamiento en el último año considerado (European Commission 2014c: 178) lo que conduce al descenso de la dependencia exterior relativa al gas. Por detrás de Letonia se encuentra Grecia (que aumentó su seguridad energética en un 9,9\% gracias a la diversificación de sus proveedores de gas) y Eslovaquia, que ha mejorado la seguridad del suministro después de la crisis del gas de 2009 mediante el establecimiento de grandes capacidades de flujo inverso que podrían cubrir su demanda anual, siempre que haya suficientes fuentes y capacidades desde Europa Occidental (European Commission 2014c: 255). En el lado opuesto se encuentran Bulgaria y Polonia con un descenso del $9,7 \%$ y $6,9 \%$ respectivamente. Los factores que explican estos retrocesos es que presentan un declive de la estabilidad geopolítica de sus compras de gas y de la diversificación de suministradores, y un incremento de la dependencia. Estos hechos tienen como consecuencia un crecimiento del riesgo de interrupción de suministro.

\section{CONCLUSIONES}

Este artículo ha pretendido añadir una nueva evidencia empírica a la literatura sobre un tema de actualidad: la seguridad de abastecimiento energético. Concretamente se ofrece evidencia acerca de la seguridad para el gas en la UE, una fuente básica de energía. Este asunto es importante dada la coyuntura presente y de los últimos tiempos relacionada con las discrepancias por el gas entre Rusia y Ucrania, lo que ha llevado a renovar el interés por la seguridad energética en la Unión. Una lección de este acontecimiento geopolítico es que para que las medidas sean coherentes y eficaces deben estar estipuladas con antelación y coordinarse a escala comunitario para enfrentarse a las suspensiones a corto plazo y habilitar las infraestructuras oportunas en el largo plazo (European Commission, 2009b: 1). 
Fernández, Ana; Rodríguez, Laura. Seguridad de abastecimiento energético en la Unión Europea en el contexto del conflicto gasista ruso-ucraniano.

La seguridad del suministro es una de las principales finalidades de la política energética en muchos lugares de todo el mundo, entre ellos la UE. Dentro de la literatura académica emerge un amplio abanico de definiciones referente a esta temática que se han ido renovando con el tiempo. Además se trata de un concepto complejo y multidimensional, por lo que algunos expertos afirman que es un término borroso y difícil de alcanzar.

En el marco de la política energética europea la seguridad de abastecimiento representa un notable reto. Palazuelos (2008: 153-154) afirma que la liberalización del gas ha modificado la configuración de los mercados, ha hecho que Gazprom mejore sus relaciones con varios países de la UE y que la falta de una táctica común deriva en que los gobiernos y las grandes sociedades de cada nación sean los que establezcan las pautas para asegurar el abastecimiento de gas. Este autor agrega que existe una disparidad de estrategias empresariales y nacionales que tienen un acentuado carácter bilateral y que la ausencia de una política universal en la Unión tiene, entre otros, los siguientes desenlaces: el enfrentamiento con el consenso de los Estados en torno a unos fines y unas acciones comunes; la Unión Europea no posee la capacidad de actuar directamente en los acuerdos entre empresas y gobiernos nacionales al carecer de una institución que se encargue del sector del gas; y que la negativa de admitir que Rusia es el principal socio energético del conjunto de la Unión propaga problemas complementarios que perjudican a las regiones europeas y beneficia a Rusia.

De igual modo, el mercado interno del gas natural es una pieza clave para aumentar esta seguridad y mitigar la exposición de los países a los impactos adversos de los cortes de aprovisionamiento. De hecho, la creciente dependencia energética de la última década acarrea la posibilidad de paradas de suministro. En esa etapa, Rusia ha sido el surtidor más señalado de combustibles fósiles, petróleo crudo y gas natural para la UE-28, existiendo seis territorios que dependen íntegramente del gas ruso: Bulgaria, Estonia, Eslovaquia, Letonia, Lituania y Finlandia.

Conviene recordar que las suspensiones de suministro representan la principal preocupación y conllevan costes económicos, sociales y ligados con la seguridad interior y exterior de las economías. A todo esto hay que sumar otro problema: las limitaciones de exportación de los países exportadores de gas. En este sentido, Rusia no pudo atender su demanda interna en 2008 por lo que interrumpió el abastecimiento a Grecia y a Turquía, es más, numerosos analistas coinciden en que Gazprom será incapaz de hacer frente a su gran cantidad de compromisos de aprovisionamiento (Bermejo, 2008: 100). Si en estos momentos se estancase el gas ruso que se dirige a la UE por medio de Ucrania, Bulgaria, Rumania, Hungría, Eslovaquia y la República Checa serían los perdedores.

Desde el punto de vista del comprador, con el fin de indagar en la situación y en el progreso de la seguridad del suministro en las zonas de la UE servidas en mayor medida por Rusia dentro del contexto de las importantes alteraciones temporales en el aprovisionamiento de gas ruso que padecieron algunos países miembros de Europa oriental durante el invierno de 2006 y 2009, se han escogido las dimensiones convenientes para construir el Índice Ponderado de Seguridad Energética del gas: la 
Fernández, Ana; Rodríguez, Laura. Seguridad de abastecimiento energético en la Unión Europea en el contexto del conflicto gasista ruso-ucraniano.

geopolítica y la vulnerabilidad (formada por la dependencia y la conectividad) con origen en el examen causal de los riesgos energéticos.

A pesar de que un indicador sintético puede resultar un poco simple puede contribuir a la hora de tomar decisiones de cara al futuro, en este caso, relacionadas con la política energética europea. En todo caso, gracias al IPSE del gas se ha podido establecer un ranking y una comparación de países que resume el problema de la seguridad energética consiguiendo así una idea simplificada de la realidad. Por todo ello, con esta investigación se verifica que se puede exhibir una representación cuantitativa de la seguridad del suministro.

Los resultados de la investigación demuestran la no concordancia con la hipótesis de partida, es decir, el nivel de seguridad energética no se ha reducido sino que ha seguido una trayectoria opuesta, ensanchándose en la mayoría de las naciones consideradas (especialmente en Letonia), a excepción de Austria, Bulgaria, Finlandia, Hungría y Polonia. Por otro lado, el peor posicionado en el ranking es Lituania y Croacia y Rumania los más sobresalientes.

Las recomendaciones para mejorar la dimensión externa de la seguridad energética de las naciones más subordinadas al gas ruso estarían ligadas con la vulnerabilidad: diversificación de distribuidores y fuentes de aprovisionamiento de gas, dados los bajos niveles de las sub-dimensiones de conectividad y dependencia de casi todos los países contemplados. En efecto, ello implicaría promover las energías renovables. De manera complementaria, ante una nueva crisis con detenciones de gas se debería potenciar la colaboración entre Estados miembros.

Por fin, la limitación más apreciable de este trabajo es que hay un sólo valor disponible del Índice de Riesgo Socioeconómico (SERI) para la fase 2000-2008, ya que no se han realizado nuevas estimaciones, por lo que se ha usado dicho valor como un parámetro representativo de todo el período. Otra restricción tiene que ver con el enfoque manejado: el geopolítico. La dimensión no nacional de la seguridad de abastecimiento se descifra en un ambiente geopolítico, pero también en el contexto económico internacional, definiéndose por las interrelaciones entre las políticas gubernamentales y los mercados, considerándose de esta manera como un asunto de índole político-económico internacional (Muñoz, 2012: 66). En suma, la seguridad energética se asienta dentro de la disciplina de la Economía Política Internacional (EPI), donde intervienen diversos actores: Estados, compañías transnacionales, organismos internacionales, etc. Una posible línea futura de investigación sería, en este sentido, el análisis de la seguridad de aprovisionamiento desde un planteamiento propio de la EPI, basado tanto en los enfoques tradicionales como, sobre todo, de los más contemporáneos. Otra posible línea de investigación consistiría en integrar en la seguridad energética el punto de vista medioambiental. Esto se traduciría en incorporar el obstáculo de los recursos fósiles (petróleo, gas natural y carbón), vinculado al momento de su techo (peak oil, peak gas, peak coal), así como las consecuencias ambientales fruto de la producción y consumo de energía que la atañen, es decir, el cambio climático. 
Fernández, Ana; Rodríguez, Laura. Seguridad de abastecimiento energético en la Unión Europea en el contexto del conflicto gasista ruso-ucraniano.

\section{BIBLIOGRAFÍA}

Alhajji, A.F. (2007): "What is Energy Security?", Middle East Economic Survey, 52 (L), $1-3$.

APERC (2007): A quest for energy security in the 21st Century, Asia Pacific Energy Research Centre, Institute of Energy Economics, Japan.

Avedillo, M. y Muñoz, M. A. (2007): "Seguridad Energética en Europa: de la percepción a la cuantificación", Boletín económico de ICE, Información Comercial Española, 2928, 43-48.

Bermejo, R. (2007): Un futuro sin petróleo, Los Libros de la Catarata/FuhemEcosocial, Madrid.

Bohi, D. R. y Toman, M. A. (1996): The economics of energy security, Kluwer Academic Publishers, Boston.

Checchi, A.; Behrens, A., y Egenhofer, C. (2009): Long-Term Energy Security Risks for Europe: A sector-Specific Approach, Working Document $N^{\circ} 309$, Center for European Policy Studies (CEPS), Brussels.

Chester, L. (2010): "Conceptualizing energy security and making explicit its polysemic nature", Energy Policy, 2 (38), 887-895, consultado en http://www.sciencedirect.com.ezproxy.uned.es/science/article/pii/S0301421509 007861 , el 29 de octubre de 2014.

Cohen, G.; Joutz, F. y Loungani, P. (2011): "Measuring energy security: Trends in the diversification of oil and natural gas supplies", Energy Policy, 9 (39), 48604869, consultado

en http://www.sciencedirect.com.ezproxy.uned.es/science/article/pii/S0301421511 004903, el 18 de noviembre de 2014.

Correljé, A. y Van der Linde, C. (2006): "Energy supply security and geopolitics: A European perspective", Energy Policy, 4 (34), 532 - 543, consultado en http://www.sciencedirect.com.ezproxy.uned.es/science/article/pii/S0301421505 003095, el 3 de octubre de2014.

Costantini, V.; Gracceva, F.; Markandya, A. y Vicini, G. (2007): "Security of energy supply: Comparing scenarios from a European perspective", Energy Policy, $\quad 1 \quad$ (35), 210-226, consultado en http://www.sciencedirect.com.ezproxy.uned.es/science/article/pii/S0301421505 003009 el 29 de octubre de 2014.

De la Cámara, M. (2009): La seguridad europea y las relaciones UE-Rusia, Análisis del Real Instituto Elcano (ARI), No 76/2009.

Diario Oficial de la Unión Europea (2007): Tratado de Lisboa por el que se modifican el Tratado de la Unión Europea y el Tratado constitutivo de la Comunidad Europea, Diario Oficial No C 306 de 17/12/2007, Bruselas.

Escribano, G. (2014): Las consecuencias energéticas del conflicto de Ucrania, Real Instituto Elcano de Estudios Internacionales y Estratégicos, Madrid.

Escribano, G. (2006): Seguridad Energética: concepto, escenarios e implicaciones para España y la UE, Real Instituto Elcano de Estudios Internacionales y Estratégicos, DT 33/2006, Madrid.

Escribano, G. y García-Verdugo, J. (2011): "Energy security, energy corridors and the geopolitical context" en Marín, J.M.; García-Verdugo, J. y Escribano, G. (eds.): Energy Security for the EU in the 21st Century: Markets, geopolitics and corridors, Routledge, London, 26-36. 
Fernández, Ana; Rodríguez, Laura. Seguridad de abastecimiento energético en la Unión Europea en el contexto del conflicto gasista ruso-ucraniano.

European Commission (2000): Green Paper Towards a European strategy for the security of energy supply, COM (2000) 769 final, Brussels.

European Commission (2006): Green paper: A European strategy for sustainable, competitive and secure energy, COM (2006) 105 final, Brussels.

European Commission (2009a): The January 2009 gas supply disruption to the EU: An assessment, Commission staff working document $\{\mathrm{COM}(2009) 363\}$, Brussels.

European Commission (2009b): Proposal for a regulation of the European Parliament and of the Council concerning measures to safeguard security of gas supply and repealing Directive 2004/67/EC, COM (2009) 363 final \{SEC(2009) 977\}, \{SEC(2009) 978\}, \{SEC(2009) 979\}, \{SEC(2009) 980\}, Brussels.

European Commission (2014a): Communication from the Commission to the Council and the European Parliament: European energy security strategy, \{SWD (2014) 330 final\}, Brussels.

European Commission (2014b): Communication from the Commission to the European Parliament and the Council on the short-term resilience of the European gas system, COM (2014) 654 final, Brussels.

European Commission (2014c): In-depth study of European Energy Security. Accompanying the document Communication from the Commission to the Council and the European Parliament: European energy security strategy, \{COM (2014) 330 final\}, Brussels.

European Commission (2014d): Questions and answers on security of energy supply in the EU, MEMO/14/379, Brussels.

Eurostat. Oficina de estadística de la Comisión Europea. http://epp.eurostat.ec.europa.eu/portal/page/portal/statistics/themes

García-Verdugo, J., y San Martín, E. (2011): "Risk theory applied to energy security. A tipology of energy risks", en Marín, J.M.; García-Verdugo, J. y Escribano, G. (eds.): Energy Security for the EU in the 21st Century: Markets, geopolitics and corridors, Routledge, London, 111-143.

García-Verdugo, J., San Martín, E. y Muñoz, B. (2011): "Quantifying geopolitical energy risk", en Marín, J.M.; García-Verdugo, J. y Escribano, G. (eds.): Energy Security for the EU in the 21st Century: Markets, geopolitics and corridors, Routledge, London, 144-169.

IEA, (2014): Energy Efficiency Indicators: Fundamentals on Statistics, OECD/IEA, París.

Kruyt, B.; Van Vuuren, D. P.; De Vries, H. J. M. y Groenenberg, H. (2009): "Indicators for energy security", Energy Policy, 6 (37), 2166-2181, consultado en http://www.sciencedirect.com.ezproxy.uned.es/science/article/pii/S0301421509 000883 el 22 de octubre de 2014.

Le Coq, C. y Paltseva, E. (2009): "Measuring the security of external supply in the European Union", Energy Policy, 11 (37), 4474-4481, consultado en http://www.sciencedirect.com.ezproxy.uned.es/science/article/pii/S0301421509 004091 el 15 de noviembre de 2014.

López, L. y Del Pozo, P.B. (1999): Geografía política, Cátedra, Madrid.

Löschel, A.; Moslener, U. y Rübbelke, D. (2010): "Energy security-concepts and indicators", Energy Policy, 4 (38), 1607-1608, consultado en http://www.sciencedirect.com.ezproxy.uned.es/science/article/pii/S0301421509 001657 el 27 de octubre de 2014.

Marín, J.M.; San Martín, E. y Serrano, S. (2012): "Factores clave de la seguridad del 
Fernández, Ana; Rodríguez, Laura. Seguridad de abastecimiento energético en la Unión Europea en el contexto del conflicto gasista ruso-ucraniano.

suministro energético", Cuadernos de energía, № 35, pp. 68-81.

Mena, D. (2013): "An approach to the concept of energy security: its link to Chile's energy policy", Revista Encrucijada Americana, 1, 65-77.

Moré, I. (2006): Rusia abre la caja de Pandora del gas, Real Instituto Elcano de Estudios Internacionales y Estratégicos, $N^{\circ} 5$, Madrid.

Muñoz, B. (2012): Turquía y la seguridad energética de la UE, Universidad Nacional de Educación a Distancia, consultado en http://espacio.uned.es:8080/fedora/get/tesisuned:CiencEcoEmpBmunoz/Documento.pdf el 11 de noviembre de 2014.

Palazuelos, E. (2008): El petróleo y el gas en la geoestrategia mundial, Ediciones Akal, Madrid.

Parlamento Europeo (2010): Reglamento (UE) No 994/2010 de 20 de octubre de 2010 sobre medidas para garantizar la seguridad del suministro de gas y por el que se deroga la Directiva 2004/67/CE del Consejo, Bruselas.

Pérez, F.; Blancas, F.J.; González, M.; Guerrero, F. M., Lozano, M. y Ruiz, M. (2008): "Análisis, diseño y comparación de indicadores sintéticos" en XVI Jornadas ASEPUMA - IV Encuentro Internacional, 1(Actas_16), ASEPUMA, consultado en: http://metodos.upct.es/asepuma/comunicaciones/completas/803.pdf el 14 de noviembre de 2014.

Pirani, S.; Henderson, J.; Honoré, A.; Rogers, H. y Yafimava, K. (2014): What the Ukrainian crisis means for gas markets, Oxford Institute for Energy Studies, London.

Pirani, S.; Stern, J. y Yafimava, K (2009): The Russo-Ukrainian gas dispute of January 2009: a comprehensive assessment, Oxford Institute for Energy Studies, London.

Ren, J. y Sovacool, B. (2014): "Quantifying, measuring, and strategizing energy security: Determining the most meaningful dimensions and metrics", Energy Policy, 76, 838-849, consultado en http://www.sciencedirect.com.ezproxy.uned.es/science/article/pii/S0360544214 010482 el 18 de noviembre de 2014.

Rodríguez L. y García-Verdugo, J. (2012): "Las políticas de seguridad de abastecimiento energético: Dimensiones, cuantificación y aplicación al caso español", Papeles de Economía Española, 134, 231-243.

Saisana, M., y Tarantola, S. (2002): State-of-the-art report on current methodologies and practices for composite indicator development, European Commission, Joint Research Centre, Institute for the Protection and the Security of the Citizen, Technological and Economic Risk Management Unit, Italy.

Sánchez, A. (2008): "La dependencia energética europea de Rusia", Revista ICE, $842,87-109$

Saturno, P. (2004): "La invasión de los indicadores compuestos. Riesgos y beneficios para la gestión de la calidad", Revista de Calidad Asistencial, 6 (19), 407-415.

Segoviano, S. (2011): España ante el reto de la seguridad energética, Observatorio de Política Exterior Europea, Documento de Trabajo 56/2011, Madrid.

Sovacool, B.K. (2012): "The methodological challenges of creating a comprehensive energy security index", Energy Policy, 48(1), 835-840, consultado en http://www.sciencedirect.com/science/article/pii/S0301421512001334 el 1 de marzo de 2016.

Sovacool, B.K. y Mukherjee, I. (2011): "Conceptualizing and measuring energy security: A synthesized approach", Energy Policy, 8(36), 5343-5455, 
Fernández, Ana; Rodríguez, Laura. Seguridad de abastecimiento energético en la Unión Europea en el contexto del conflicto gasista ruso-ucraniano.

consultado

en

http://www.sciencedirect.com.ezproxy.uned.es/science/article/pii/S0360544211 004294 el 30 de octubre de 2014.

Thumann, M. (2006): "Diversification des sources - la meilleure stratégie pour les relations énergétiques UE-Russie", Russie Nei Visions (ifri), No $10 \mathrm{~d}$.

Umbach, F. (2014): "El conflicto Rusia-Ucrania-UE del gas: ¿quién tiene más que perder?", Revista de la OTAN edición digital, consultado en http://www.nato.int/docu/review/2014/NATO-Energy-security-running-on-

empty/Ukrainian-conflict-Russia-annexation-of-Crimea/ES/index.htm el 4 de noviembre de 2014.

Winzer, C. (2012): “Conceptualizing energy security”, Energy Policy, 1 (46), 36-48, consultado

en:

http://www.sciencedirect.com.ezproxy.uned.es/science/article/pii/S0301421512 002029 el 30 de octubre de 2014.

Yunta, R. (2008). "El aprovisionamiento de energía: seguridad del suministro y mercados", en García, J.L. y Jiménez, J.C. (eds.): Energía y regulación en Iberoamérica, Thomson-Civitas, Madrid, 131-151.

Zapater, E. (2009): "La seguridad energética de la Unión Europea en el contexto de la nueva política energética y el tratado de Lisboa", en Morata, F. (coord.): Energía del siglo XXI: Perspectivas europeas y tendencias globales, Institut Universitari D’Estudis Europeus, Barcelona, 49-79. 